\title{
IDENTIFIKASI MATERIAL SCAFFOLDING SEBAGAI ALTERNATIF TEMPAT TINGGAL UNTUK KALANGAN MASYARAKAT BERPENGHASILAN RENDAH (MBR) Studi kasus di Akanoma Studio
}

\author{
Suharyani Suharyani \\ Program Studi Arsitektur \\ Universitas Muhammadiyah Surakarta \\ Email : yani.ummumufti@gmail.com
}

\section{Mutya Nor Fathonah}

Program Studi Arsitektur

Universitas Muhammadiyah Surakarta

Email :mutyanfath@gmail.com

\begin{abstract}
ABSTRAK
Mahalnya material yang digunakan untuk membangun tempat tinggal berimbas pada harga perumahan yang juga melambung tinggi. Hal ini yang dirasakan kalangan masyarakat berpengahasilan rendah (MBR) sehingga mereka terpaksa membangun hunian kurang layak seperti membangun di lingkungan kumuh menggunakan kardus, di bawah kolong jembatan, bantaran sungai, bahkan membangun di lahan yang ilegal. Belum lagi harus berurusan dengan cicilan kredit yang melibatkan bunga bank. Solusi alternatif hunian yang hemat biaya dan efisien bagi warga yang kurang mampu sangat diperlukan. Rumah Scaffolding yang memanfaatkan material alternatif sebagai struktur utama, dikembangkan oleh arsitek dari Akanoma Studio. Metode penelitian yang digunakan adalah metode kualitatif, merujuk pada riset yang bersifat deskriptif dan cenderung menggunakan analisa dari sumber-sumber terpercaya. Selain itu untuk mendapatkan data yang diperlukan, dilakukan juga interview jarak jauh dengan arsitek penemu gagasan rumah scaffolding di Akanoma Studio. Hasil dari penelitian ini berupa pengetahuan keunggulan material scaffolding sebagai bahan utama pembuatan rumah hemat biaya dan gambaran perencanaan pembangunan rumah scaffolding, yang akan ditujukan untuk masyarakat berpenghasilan rendah. Keberadaan rumah scaffolding diharapkan dapat membantu meyediakan fasilitas berupa hunian untuk sementara sebelum bisa membangun rumah yang lebih baik dan juga membantu menghindari terjadinya riba karena kredit rumah yang mahal.
\end{abstract}

KATA KUNCI : scaffolding; rumah tinggal; rumah murah

\section{PENDAHULUAN}

Rumah dan sarana pemukiman saat ini adalah pusat perhatian utama negara - negara di dunia. Indonesia merupakan negara kepulauan yang memiliki luas wilayah $+1,905$ juta $\mathrm{km}^{2}$ dengan jumlah penduduk mencapai 265 juta jiwa yang membutuhkan tempat tinggal. Rata-rata penghasilan yang didapatkan kurang lebih 4 juta/jiwa, dan masih banyak yang di bawah strandar tersebut. (BPS 2016) Menurut data, untuk membangun tempat tinggal dibutuhkan dana yang cukup besar. Mahalnya harga perumahan juga membuat masyarakat di kalangan menengah ke bawah membangun tempat tinggal kurang tertata dengan material seadanya. Bahkan banyak masyarakat di Indonesia khususnya daerah perkotaan membangun tempat tinggal di atas tanah yang ilegal.

Data dari Badan Pusat Statistik (BPS) pada tahun 2016, 74 \% penduduk Indonesia tinggal di Kota dan akan terus meningkat pada tahun mendatang. Akibatnya banyak masyarakat yang menempati atau membangun rumah di lahan yang ilegal, munculya rumah-rumah kumuh dan tidak tertata. Menanggapi hal tersebut Kementrian Pekerjaan Umum dan Perumahan Rakyat (PUPR) menyebutkan salah satu upaya pemerintah mengatasinya adalah dengan menyediakan sarana pemukiman dan rumah, khususnya bagi masyarakat menengah ke bawah. Namun dalam pelaksanaanya, penduduk menengah ke bawah juga harus membayar cicilan rumah yang mahal, belum lagi cicilan sebagian besar menggunakan bunga. MUI mengeluarkan fatwa pengharaman bunga (riba) diantaranya Fatwa DSNMUI no.1 tahun 2004. Di dalam Qur'an Surat AlBaqarah ayat 279 juga disebutkan "..... maka ketahuilah, bahwa Allah dan Rasul-Nya akan memerangimu (disebabkan tidak meninggalkan sisa riba)". Oleh karena itu, untuk mengindari hal-hal negatif di atas, penulis meneliti tentang Rumah Scaffolding rancangan seorang arsitek dari Akanoma Studio sebagai alternatif rumah tinggal hemat biaya untuk kalangan masyarakat berpenghasilan rendah dengan ekonomi syariah tanpa dibebani hutang, 
sebanyak mungkin mengindari riba dan diharapkan dapat mengembangkan potensi yang ada.

Kemudian untuk mengetahui informasi dan data yang dibutuhkan dilakukan wawancara kepada arsitek yang memiliki gagasan untuk membuat Rumah Scaffolding.

\section{Rumusan Masalah}

Apa keunggulan scaffolding sebagai material alternatif pembangunan tempat tinggal?

\section{Tujuan Penelitian}

Mengetahui material alternatif untuk pembangunan rumah dan keunggulan menggunakan bahan scaffolding.

\section{Manfaat Penelitian}

Memberikan pengetahuan tentang kriteria material alternatif yang efektif untuk membangun tempat tinggal.

\section{Metode Penelitian}

a. Studi Pustaka

Studi pustaka diperoleh dari beberapa sumber seperti buku, jurnal ilmiah, laporan penelitian maupun liputan media masa. Sebagai referensi berdasarkan keterkaitan isi buku dengan permasalahan yang dikaji dalam penelitian ini.

b. Interview

Interview adalah proses pencarian data dengan melakukan wawancara dengan narasumber untuk mengumpulkan responden.

c. Dokumentasi

Dokumentasi digunakan untuk mengambil gambar dari objek yang diamati serta sebagai bukti bahwa telah melakukan penelitian.

\section{Penelitian Terkait}

Referensi yang digunakan dari berbagai peneliti sudah ada antara lain hasil penelitian Khabib Ikhsanudin (2017) dengan judul Dasar Program Perencanaan Dan Perancangan Arsitektur (Dp3a) Tanjung Emas Container Apartment menghasilkan kesimpulan bahwa sebagai salah satu cara untuk mengatasi kepadatan penduduk dan dapat juga menjadi fasilitas hunian untuk para pekerja pelabuhan yang membutuhkan tempat tinggal yang dekat dengan tempat mereka bekerja. Penelitian Rully (2014) Dengan judul Merencanakan dan Merancang Rumah Tinggal yang Optimal, halaman 13. Dan Rumah Scaffolding dari Akanoma Studio.

\section{KAIIAN PUSTAKA}

\section{Rumah Tinggal}

Pengertian Rumah Tinggal

a. Menurut UU No. 4 Tahun 1992 Tentang Perumahan dan Permukiman, Rumah merupakan bangunan yang berfungsi sebagai hunian atau tempat tinggal serta sebagai sarana pembinaan keluarga.

b. Dalam arti luas, rumah tidak hanya bangunan struktural, akan tetapi tempat tinggal yang memenuhi syarat-syarat kehidupan layak yang dipandang dari berbagai segi kehidupan masyarakat. Rumah sebagai tempat perlindungan, untuk menikmati kehidupan, beristirahat dan bersuka ria bersama keluarga. Di dalam rumah, penghuni memperoleh kesan pertama dari kehidupannya di dalam dunia ini. Rumah harus menjamin kepentingan keluarga, yaitu untuk tumbuh, memberi kemungkinan untuk hidup bersosial dengan tetangganya, dan lebih dari itu, rumah harus memberikan ketenangan, kesenangan, kebahagiaan, dan kenyamanan pada segala peristiwa hidup. (Frick, $2006: 1)$

\section{Fungsi Rumah Tinggal}

A.Turner (dalam Jenie, 2001 : 45), mendefinisikan ada tiga fungsi utama sebuah rumah, antara lain:

a. Rumah sebagai penunjang identitas keluarga (identity) yaitu diwujudkan pada kualitas hunian dengan perlindungan yang diberikan oleh rumah. Kebutuhan akan tempat tinggal dimaksudkan agar penghuni dapat memiliki tempat berteduh untuk melindungi diri dari iklim setempat.

b. Rumah sebagai penunjang kesempatan (opportunity) keluarga berperan penting dalam kehidupan sosial budaya dan ekonomi atau fungsi pengemban keluarga. Kebutuhan berupa akses dalam pemenuhan kebutuhan sosial dan kemudahan ke tempat kerja guna mendapatkan sumber penghasilan.

c. Rumah sebagai penunjang rasa aman (security) dalam arti terjaminnya keadaan keluarga di masa depan setelah mendapatkan rumah. Jaminan keamanan atas lingkungan perumahan yang ditempati serta jaminan keamanan berupa kepemilikan rumah dan lahan (the form of tenure).

\section{Jenis Rumah Tinggal}

Menurut Richard Untermann \& Robert Small (1986) dalam buku Perencanaan Tapak untuk Perumahan, maka ada beberapa tipe perumahan antara lain:

\section{a. Rumah Tinggal Tunggal (Detached)}


Rumah tinggal tunggal atau rumah terpisah adalah rumah tinggal yang berdiri sendiri.

b. Rumah Tinggal Koppel (Semi Detached)

Rumah Tinggal kopel adalah Rumah Tinggal Tunggal yang di sekat sama besar antara kiri dan kanan.

c. Rumah Kota (Town House)

Sama seperti rumah gandeng dengan penambahan tempat parkir di dalam bangunannya.

d. Rumah Susun (Flat)

Rumah yang fleksibel, yaitu mampu menyesuaikan berbagai konfigurasi.

e. Rumah Berpekarangan Dalam (Patio House)

Adalah suatu variasi pada rumah "ranch" berlantai satu tradisional.

f. Maisonet (Maisonette)

Adalah sebuah tipe standar dari bangunan berkapasitas tinggi dan bertingkat rendah.

g. Rumah Teras Bertingkat (Terrace House)

Rumah gandeng dan berpekarangan dalam dapat saja dibuat menjenjang ke atas maupun ke bawah.

h. Rumah Gandeng (Row Houses)

Rumah gandeng berasal dari rumah berlantai dua tradisional yang terletak di atas sebidang petak yang sempit.

\section{Syarat Rumah}

Berdasarkan pedoman teknis penilaian rumah sehat Direktorat Jendral Pengendalian Penyakit dan Penyehatan Lingkungan Depkes RI tahun 2007, syarat rumah sehat antara lain :

a. Lantai

Lantai tidak bedebu pada musim kemarau dan tidak lembab pada musim hujan. Lantai yang basah dan berdebu merupakan sarang penyakit.

b. Atap

Memilih material atap yang sesuai dengan iklim, karena Indonesia masuk wilayah tropis maka banyak menggunakan atap genteng, daun kelapa atau yang lainnya dengan posisi miring agar air hujan dapat mengalir ke bawah.

c. Ventilasi

Terdapat ventilasi yang cukup pada hunian. Ada 2 macam ventilasi yaitu ventilasi alami (aliran udara di dalam ruangan terjadi secara alamiah melalui jendela, pintu, lubang angin, dan lubang pada dinding) dan ventilasi buatan (menggunakan alat khusus untuk mengalirkan udara seperti kipas angin dan Air Conditioner). Walaupun ada alternatif ventilasi buatan, akan tetapi setiap hunian wajib membuat ventilasi alami.

d. Pencahayaan
Rumah yang sehat memerlukan cahaya yang cukup. Pencahayaan dibedakan menjadi 2 yaitu pencahayaan alami (dari sinar matahari) dan cahaya buatan (dari lampu).

e. Luas Bangunan Rumah

Luas lantai bangunan harus cukup untuk penghuni di dalamnya, agar tidak terjadi kesesakan (overcrowded).

f. Fasilitas di dalam Rumah

Di dalam rumah sehat harus terdapat fasilitas sebagai berikut :

- Penyediaan air bersih yang cukup

- Pembuangan tinja

- Pembuangan air limbah

- Pembuangan sampah

- Fasilitas dapur

- Ruang berkumpul keluarga

\section{Scaffolding \\ Pengertian Scaffolding}

Perancah merupakan alat bantu konstuksi pada pembangunan. Istilah "perancah" sering disamakan dengan "scaffolding" sejak zaman Shakespeare ketika mulai menggunakan kuda-kuda pada saat mendirikan pelat. Perancah sudah digunakan selama 5000 tahun, sejak manusia ingin membangun sesuatu yang lebih tinggi daripada yang dapat mereka capai (Robert T. Ratay, 1996).

Komponen-komponen yang ada dalam satu Scaffolding antara lain:

a. Main Frame

Main frame adalah bagian dari scaffolding yang berperan sebagai komponen utama. Fungsi main frame untuk mengatur ketinggian dan lebar scaffolding yang akan dirangkai sesuai dengan kebutuhan bangunan.

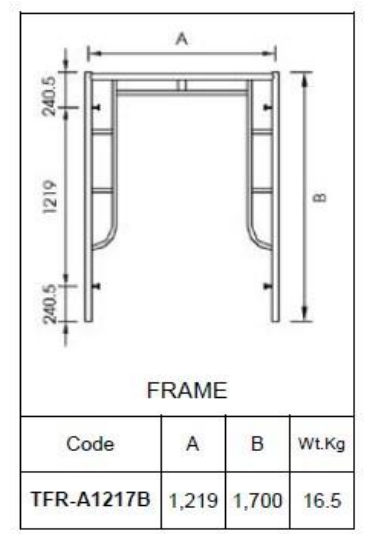

Gambar 1. Main Frame

(Sumber : https://goo.gl/images/V1FLQU) 
b. Diagonal Bracing atau Cross Brace

Merupakan bagian dari kelengkapan scaffolding yang berfungsi untuk memberikan jarak horizontal antar main frame sekaligus sebagai pengaku scaffolding agar tidak goyang. Cross brace terdiri dari 2 pipa yang saling bersilangan yang dihubungkan pada tengahnya, digunakan sebagai pengikat antara masing-masing main frame sehingga main frame dapat berdiri tegak. Selain itu, cross brace juga dapat mengurangi faktor tekuk yang terjadi pada standard scaffolding terutama jika main frame disambungkan ke atas. Pemasangan bracing relatif mudah yaitu dengan memasukkan pen yang ada di tiap-tiap frame ke lubang yang tersedia pada cross brace kemudian dikunci dengan brace locking yang ada di badan main frame.

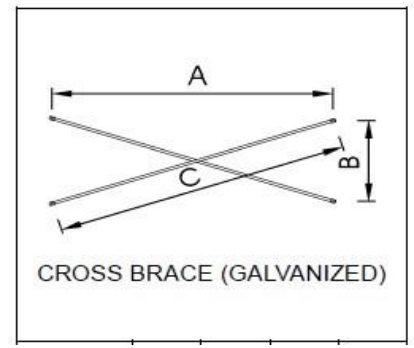

Gambar 2.Cross Brase

(Sumber : https://goo.gl/image/gpQ10)

\section{c. Adjustable Jack atau Jack Base}

Merupakan bagian dari scaffolding yang berfungsi sebagai kaki dari main frame yang dapat pula diatur ketinggiannya untuk menambah ketinggian scaffolding sesuai dengan ketinggian yang dibutuhkan. Jack base ini juga berfungsi sebagai bagian yang meratakan ketinggian scaffolding agar main frame dapat bediri dengan ketinggian yang rata.

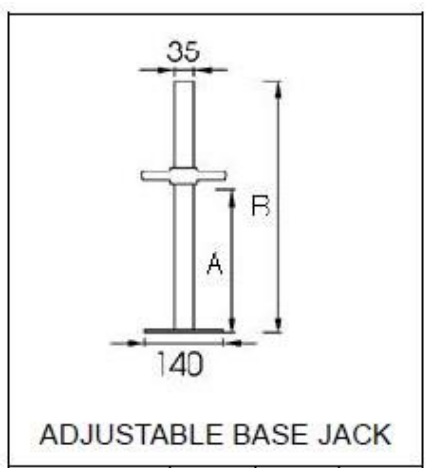

Gambar 3. Jack base

(Sumbe :https://goo.gle/images/Zj7QJa )

\section{d. Brace Locking}

Terletak di badan main frame yang memiliki fungsi sebagai pengunci antara main frame dan cross brace sehingga kedua bagian tersebut dapat terikat.

e. Joint Pin

Berfungsi sebagai penyambung dan pengunci antar suatu main frame dengan main frame di atasnya.

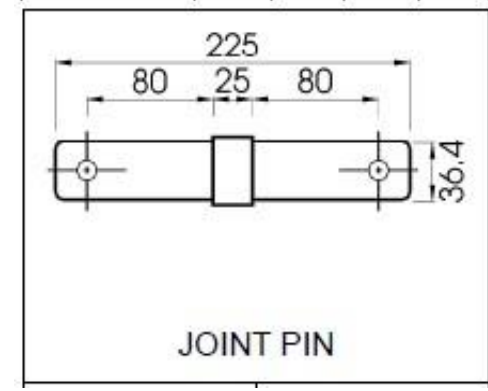

Gambar 4. Joint Pin

(Sumber : https://goo.gl/images/mDr8dt)

f. Catwalk atau deck atau platform

Merupakan bagian dari scaffolding yang berfungsi sebagai tempat berpijak antar main frame yang digunakan untuk akses para pekerja.

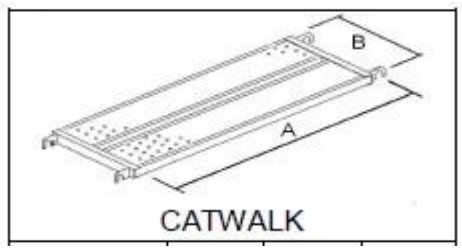

Gambar 5. Catwalk

(Sumber :https://goo.gl/images/XoUoZt)

g. U-head

Merupakan bagian teratas dari scaffolding karena fungsinya untuk menahan balok suri (balok yang menyalurkan beban-beban dari bekisting ke scaffolding) yang juga dapat diatur ketinggiannya sama seperti adjustable jack atau jack base. Bagian ini disebut u-head karena bentuknya yang menyerupai huruf $U$ dan dipasang di bagian atas. Dalam pemasangannya, pipa screw $u$-head disambungkan ke main frame kemudian dikunci, sedangkan bagian yang berbentuk $U$ dipasangkan balok suri (balok perantara) yang lebarnya sesuai dan pas dengan ukuran $u$-head yang digunakan yang nantinya akan dipasangkan bekisting di bagian atasnya. 


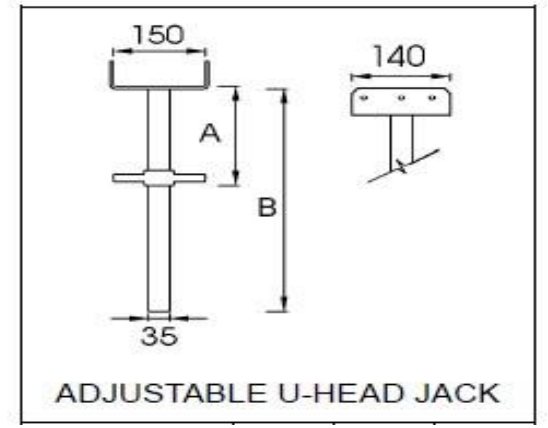

Gambar 6. U-head

(Sumber :https://goo.gl/images/mo8ahV)

Perencanaan penggunaan scaffolding harus memenuhi standart dan juga aspek teknologi, yang mana harus memenuhi persyaratan sebagai berikut:

1. Ekonomis.

2. Kuat dan kokoh.

3. Tempat berpijak harus kuat.

4. Mudah dipasang dan dibongkar.

5. Hubungan antara scaffolding dan tempat berpijaknya harus sempurna.

6. Sambungan-sambungan yang ada harus sempurna.

\section{Alternatif Material Recycle untuk Desain Hunian Rumah Container sebagai Hunian, Semarang}

Tanjung Emas Container Apartment adalah sebuah hunian vertikal yang memanfaatkan material peti kemas (Container) sebagai alternatif material bangunan yang berada di lingkungan perindustrian pelabuhan Tanjung Emas, Semarang. Pelabuhan Tanjung Emas Semarang berperan sebagai pusat transportasi dari skala lokal sampai skala internasional. Hal itu menyebabkan timbulnya kesadaran bahwa keberadaan tenaga kerja memiliki peran sangat penting dalam aktifitas pelabuhan. Sehingga besarnya jumlah tenaga kerja dapat menimbulkan dampak peningkatan kebutuhan tempat tinggal atau hunian. Selain itu keberadaan pelabuhan juga akan mengundang masyarakat untuk bermukim di lingkungan sekitar pelabuhan yang akan menimbulkan semakin padatnya pemukiman yang berada di lingkungan pelabuhan. (Ikhsanudin, 2017)

\section{Gagasan}

Gagasan Perancangan Tanjung Emas Container Apartment memiliki fungsi sebagai hunian (tempat tinggal) dengan konsep ramah akan lingkungan dan dilengkapi dengan fungsi penunjang yang berkaitan sehingga dapat membentuk pola hidup yang ramah terhadap lingkungan. Selain sebagai hunian, perencanaan dan perancangan bangunan Tanjung Emas Container Apartment juga meliputi pusat perdagangan dan perpustakaan. Perencanaan dan perancangan Tanjung Emas Container Apartment menggunakan pendekatan arsitektur kontemporer dengan bentuk kubisme.
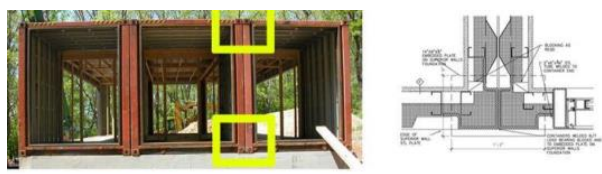

Gambar 7. Rumah Container

(Sumber :Tanjung Emas Container Apartment, 2017)

\section{Fungsi}

Fungsi bangunan yang dirancang merupakan sebuah hunian (tempat tinggal) dengan konsep ramah lingkungan dan dilengkapi dengan fungsi penunjang yang berkaitan sehingga dapat membentuk pola hidup yang ramah terhadap lingkungan.

\section{Peran}

Tanjung Emas Container Apartment mempunyai peran sebagai suatu bentuk konsep mengenai hunian vertikal di lingkungan industri perkotaan dalam rangka penataan ruang perkotaan yang bersifat jangka panjang menuju pembangunan kota yang berkelanjutan. Dalam pembangunan suatu kota tersebut terintegrasi dengan adanya tiga aspek utama yaitu ekonomi, sosial, dan lingkungan, dimana ketiga aspek tersebut harus berjalan secara bersama/ seimbang agar tujuan berkelanjutan dapat tercapai.

\section{Lingkup dan Sasaran}

Sasaran Tanjung Emas Container Apartement adalah semua kalangan masyarakat di Kota Semarang terutama kalangan menengah ke bawah. Mulai dari kalangan pekerja industri yang jumlahnya semakin meningkat dan kalangan warga yang berada di pemukiman kumuh yang memiliki hunian yang sudah tidak layak huni, karena banyak sekali pemukikan kumuh yang berada di daerah pesisir. Tidak hanya kumuh akan tetapi juga sering terkena genangan air. Maka dengan adanya hunian vertikal apartemen ini yaitu untuk menyediakan sebuah hunian yang efektif dan terjangkau bagi mereka yang membutuhkan hunian yang layak.

\section{Rumah Rempah Karya, Solo}

Rempah mengandung arti remukan sampah. Jadi rumah rempah karya ini sebagian besar dibangun menggunakan material bekas. Berawal dari pemilik rumah yaitu bapak Paulus akan membuat gudang baru. Namun di sisi lain, banyak material bekas di gudangnya sangat banyak, kemudian timbul ide untuk memanfaatkan kembali material tersebut. Banyak batang baja dengan berbagai dimensi panjang dimanfaatkan untuk rangka utama bangunan, tanpa 
harus megubahnya. Artinya material yang ada membentuk bangunan dengan kreatifitas yang harmoni. Potongan-potongan kayu ditempelkan apa adanya hingga membentuk dinding yang artistik. Sementara lantai bagian atas yang dibentuk mezzanine menggunakan alas bambu, kemudian ditambahkan anyaman bamb dan Styrofoam atau polystyrene dengan finishing plester semen. Akhirnya sebagian besar sisa material bekas berubah menjadi sebuah rumah yang penuh cita rasa seni, namun bukan sebagai rumah huni melainkan bengkel kerja untuk berbagai kegiatan kreatif dalam bidang kesenian maupun kebudayaan.
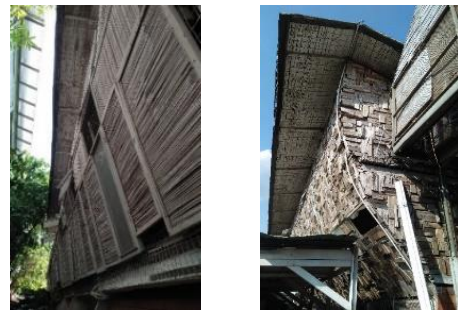

Gambar 8. Rumah Rempah

(Sumber : dokumen pribadi, 2018)

\section{Rumah Scaffolding, Studio Akanoma - Bandung}

Rumah mikro berukuran 2,5 kali tiga meter karya arsitek Benyamin Narkan. Lokasinya berada di belakang Studio Akanoma, Padalarang, Bandung Barat, Jawa Barat.Arsitek Yu Sing mendesain rumah mikro. Ukuran yang ekstrem tapi ternyata cukup memenuhi kebutuhan sehari-hari. Sebelumnya rumah ini dibuat karena masalah-masalah yang muncul saat klien meminta rumah standart huni dengan biaya yang minim (sekitar 200-300 juta). Karena banyaknya permintaan tersebut, timbulah ide untuk membuat rumah yang low budget namun layak huni dan terciptalah rumah scaffolding ini.

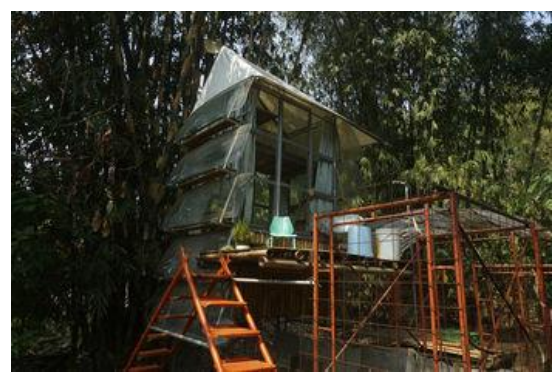

Gambar 9. Rumah Scaffolding-Studio Akanoma Bandung (Sumber : dokumen penulis,2018)

Material utama yang digunakan adalah scaffolding atau perancah, kemudian dindingnya tembus pandang berbahan kaca dan pintu gesernya dengan tirai penutup di dalam. Selain memakai bingkai aluminum berkaca, Yu Sing memasang kacakaca mobil bekas seukuran yang dibariskan vertikal di kedua samping bangunan. Seluruh posisi kaca mobil pada bingkai aluminium terbuka di bagian bawah dengan pot-pot tanaman berjejer di bagian itu. Dari sela itu sirkulasi udara mengalir.Rangka tulang untuk atap dari baja ringan. Rumpun bambu yang jangkung membantu menaungi rumah itu dari terik matahari. Rumah mikro ini dinilai ekonomis dengan harga membangunnya Rp15 juta.

\section{METODE PENELITIAN}

\section{Metode Umum}

Pada penelitian ini penulis menggunakan metode kualitatif, yaitu penelitian yang merujuk pada riset bersifat deskriptif dan cenderung menggunakan analisa. Proses pengumpulan data lebih ditonjolkan dalam metode kualitatif. Landasan teori digunakan sebagai pemandu proses penelitian, memberikan gambaran umum tentang latar penelitian agar fokus penelitian sesuai dengan fakta pada lapangan dan sebagai bahan pembahasan dari hasil penelitian. Anggapan yang mendasari penelitian dengan metode kualitatif adalah kenyataan atau fakta sebagai sesuatu yang berdimensi banyak, kesatuan dan berubah-ubah (Nana Sudjana dan Ibrahim, 2001:7). Oleh karenanya tidak mungkin bisa disusun hasil penelitian yang rinci.

Selain metode yang dijelaskan di atas, pada penelitian ini juga menggunkan metode wawancara dengan narasumber. Wawancara dilakukan untuk mendapatkan informasi yang lengkap untuk membuat laporan seminar penelitian ini.

\section{Fokus Penelitian}

Fokus penelitian ini tentang rumah scaffolding yang dijadikan hunian bagi masyarakat masyarakat ekonomi rendah. Faktor kualitas yang dimiliki material scaffolding yang diperkirakan bagus dan kuat menjadi point utama yang dipertimbangkan mengapa memilih menggunakan material ini. Kemudian memfokuskan perkembangan yang dilakukan setelah pembagunan rumah scaffolding dengan mendesain lebih kreatif dengan material yang ekonomis.

\section{Proses Penelitian}

1. Tahap Persiapan

Dilakukan identifikasi terhadap data primer dan data sekunder serta literatur yang diperlukan dalam penyusunan laporan. Untuk mendapatkan data-data tersebut, maka perlu dipersiapkan:

a. Perumusan masalah, tujuan dan sarana penelitian. Penelitian bertujuan untuk mengetahui cara pembangunan rumah scaffolding sebagai hunian yang layak untuk masyarakat berpenghasilani rendah.

b. Inventaris data 
Berupa kumpulan data temuan yang pernah dilakukan sebelumnya. Tahap ini berguna sebagai gambaran penelitian yang akan diproses sekaligus untuk menyusun strategi pengumpulan data dan informasi untuk tujuan penelitian studi ini.

\section{Tahap Pengumpulan Data}

Penulis mengumpulkan data yang didapat dari narasumber langsung yaitu arsitek di studio akanoma. Melalui proses penelitian dan pengamatan data disajikan dalam bentuk informasi tertulis. Dilakukan ekperimen pembuatan rumah scaffolding yang berada di lokasi belakang studio akanoma sendiri, yang kemudian digunakan untuk kantor studio akanoma.

3. Perlengkapan Penelitian

Beberapa alat untuk mendukung proses penelitian ini antara lain:

a. Kamera

digunakan untuk keperluan dokumentasi data pada objek penelitian.

b. Alat Tulis digunakan untuk keperluan mencatat data yang diperoleh.

c. Laptop

digunakan sebagai alat untuk mengolah data yang didapatkan dari proses observasi dan mencatat data primer di lapangan, serta menunjang proses analisis dan kelengkapan laporan.

\section{ANALISIS DAN PEMBAHASAN \\ Pengenalan Rumah Scaffolding}

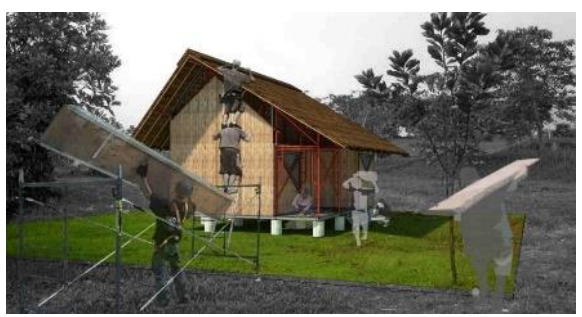

Gambar 10. .Rumah Scaffolding- Studio Akanoma Bandung

(Sumber : akanoma studio, 2018)

RumahScaffolding adalah rumah yang dibangun menggunakan material perancah atau scaffolding sebagai alternatif material utamanya, tanpa menggunakan dinding beton bahkan batu bata melainkan scaffolding dilapisi dengan anyaman bambu "gedhek" atau bisa juga menggunakan kaca atau bahan seadanya yang dapat digunakan untuk menutup bangunan. Yu Sing adalah seorang arsitek yang mengembangkan rumah saffolding ini, dia telah melakukan eksperimen pembangunan rumah scaffolding di belakang Studio Akanoma, Padalarang, Bandung Barat, Jawa Barat.

Gambar

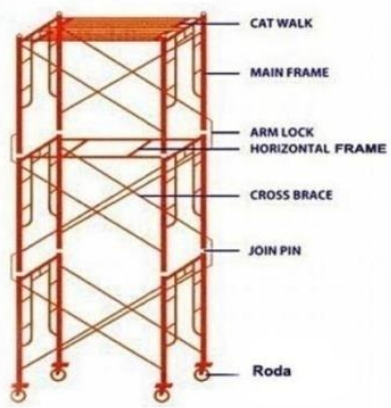

Scaffolding

11.

(Sumber : $\underline{\text { https://goo.gl/images/82TmTr) }}$

Alasan scaffolding dipilih sebagai material utama bangunan adalah :

1. Dapat dirakit dengan cepat dan mudah.

Mudah dirakit karena scaffolding sendiri didesain untuk membantu pekerjaan struktur seperti menopang bangunan, terdapat lubang penyambung sehingga memudahkan untuk dibongkar-pasang.

2. Tersedia di seluruhkota besar.

Scaffolding hampir tersedia di seluruh wilayah Indonesia, baik itu dijual baru maupun bekas.

3. Ukuran modulnya cukup nyaman untuk ruang gerak.

Hal ini diketahui dengan percobaan pembangunan yang dilakukan Yu Sing (arsitek studio akanoma), dimana scaffolding dapat berfungsi sebagai struktur rumah dengan konstruksi berbeban ringan, dapat dibongkar pasang dan dapat bertumbuh atau dikembangkan. Untuk membuat rumah scaffolding yang lebih besar hanya dibutuhkan penambahan susunan scaffolding, sehingga rumah ini mudah untuk dikembangkan.

Dengan spesifikasi dan keunggulan yang dimiliki scaffolding, maka perancangan tempat tinggal hemat biaya dapat dilakukan dengan mendesain rumah scaffolding. Seperti gagasan yang telah direalisasikan oleh Pak Yu Sing, berikut ini adalah konsep dan langkah-langkah penggarapan rumah scaffolding.

\section{Material dan Konsep}

Adapun material utama yang digunakan antara lain :

1. Scaffolding tipe 1

2. Scaffolding tipe 2

3. Wiremesh

4. Semen

5. Pasir

6. Anyaman bambu 
7. Kayu lokal

8. Daun sagu

Material utama yang digunakan untuk membangun rumah scaffolding.Scaffolding yang digunakan untuk percobaan adalah scaffolding baru, namun dapat juga menggunakan scaffolding bekas. Kemudian semua material dikumpulkan sehingga membentuk konsep seperti gambar di bawah ini :

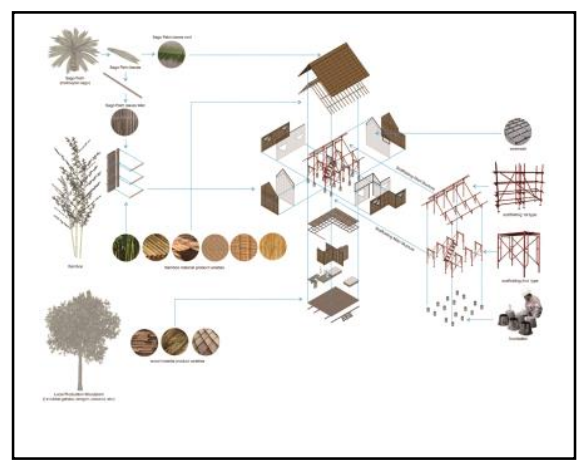

Gambar 12. Material konsep

(Sumber : akanoma studio, 2018)

Rumah scaffolding dibangun menggunakan material lokal, karena bahan lokal dapat mengurangi biaya transportasi, mendukung memajukan perekonomian daerah dan melestarikan budaya tradisional. Penggunaan bahan alami akan membantu penghuni mengetahui akan terjadinya gempa dan mengisyaratkan untuk segera meninggalkan rumah. Karena bahan seperti kayu dan bambu bersifat fleksibel, sehingga apabila terjadi gempa material tersebut lebih kokoh dari materal lain seperti beton.

\section{Perancangan Rumah Scaffolding}

1. Atap

a. Alternatif material rangka atap

- Rangka Atap 1. Kuda-kuda bambu/ kayu lokal

- Rangka Atap 2. Kuda-kuda besi hollow

b. Alternatif material penutup atap

Menggunakan material yang relatif ringan :

- Penutup Atap 1.

Zincalum/seng/fibersemen

Alternatif insulasi panas yaitu : karung goni diisi sekam/kompos dipasang di atap dan biarkan tumbuh rumput perdu liar.Pohon rambat yang tumbuh dengan cepat misal markisa.Atap daun nipah/rumbia di atas atap zincalum / seng / fibersemen.

- Penutup Atap 2. Bitumen (onduline).

2. Dinding

a. Alternatif material dinding

Dinding yang berfungsi juga sebagai pengaku :
- Dinding 1. Wiremesh m61 lapis dicor beton berbekisting papan, tebal $7 \mathrm{~cm}$.

- Dinding 2. Zincalum/seng/fibersemen yang dapat dirambatkan pohon dari luar.

- Dinding3. Dinding daun nipah/rumbia/material lokal lainnya.

- Dinding 4. dinding papan kayu.

- Dinding 5. bambu bilah (papuluh)/ anyaman bambu.

3. Lantai

Alternatif material lantai yaitu lantai di panggung dan lantai 2 :

a. Lantai 1. Rangka baja kanal C (balok induk) dan zincalum, di atasnya wiremesh m6 1 lapis, dicor beton tebal $7 \mathrm{~cm}$.

b. Lantai 2. Rangka baja kanal C (balok induk) + besi hollow (balok anak), lalu ditutupi papan kayu lokal atau multipleks $24 \mathrm{~mm}$.

c. Lantai 3. Rangka kayu/bambu lalu ditutupi papan kayu/bambu belah (palupuh).

\section{Modul Rumah Scaffolding}

Rumah scaffolding dirancang dengan program ruang seperti hunian pada umumnya dengan menambahkan konsep islami, yaitu ruang tamu, 3 kamar tidur, kamar mandi dan dapur. Kapasitas penghuni 5-6 orang, ayah, ibu, anak dan kakek-nenek.

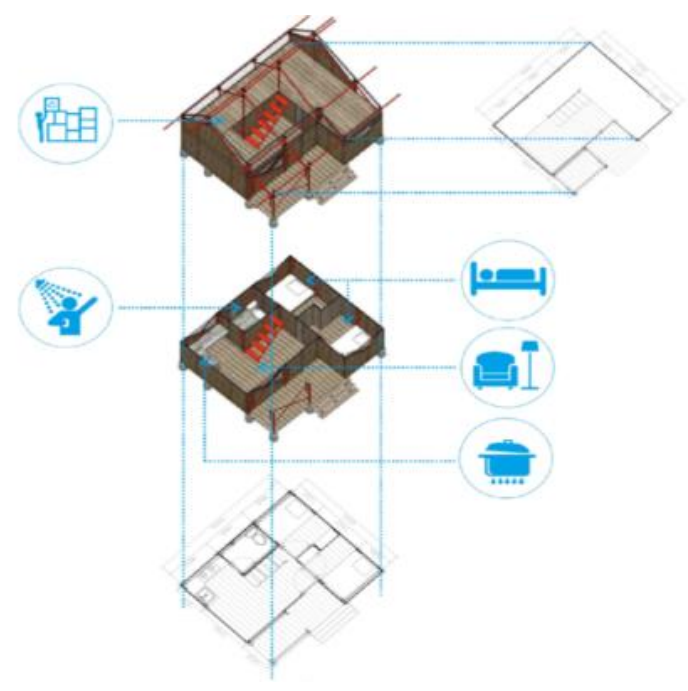

Gambar 13. Program Ruang

(Sumber : dokumen pribadi, 2018)

Ada 2 pilihan untuk perletakan dasar rumah scaffolding :

a. Di dasar tanah yang akan dibangun 


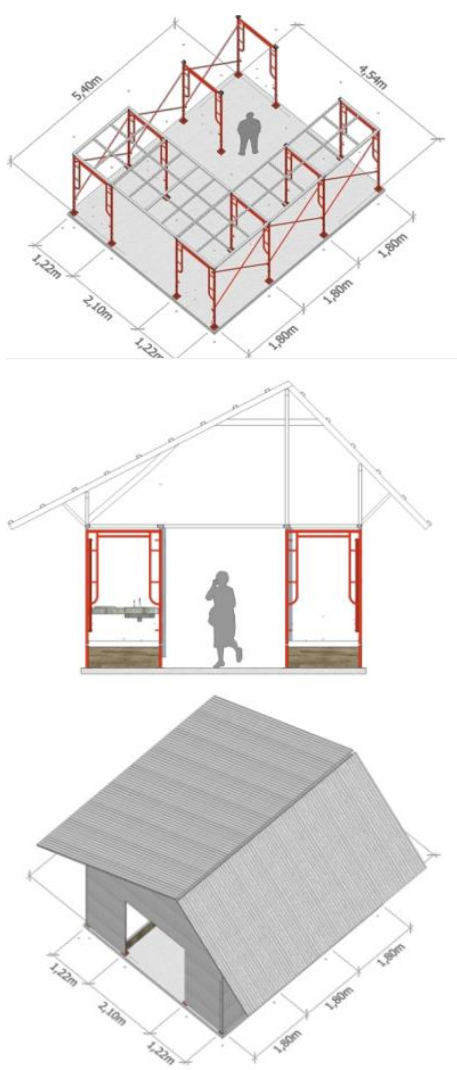

Gambar 14. Sketsa Lantai Dasar Tanah (Sumber : dokumen penulis,2018)

b. Di atas umpak beton, lantai berupa panggung

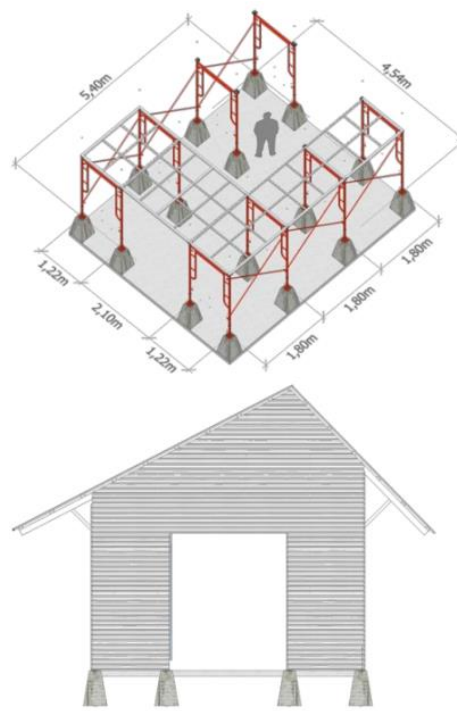

Gambar 15. Sketsa Lantai Panggung

(Sumber : dokumen penulis,2018)

Rumah scaffolding mudah untuk dimodifikasi, dengan menambah luasan atau memberikan mezzanine. Dapat dimodifikasi ke atas dan juga modifikasi ke samping.

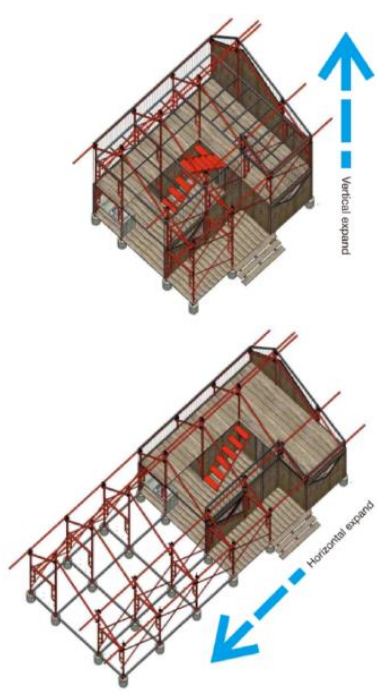

Gambar 16. Skema Modifikasi Rumah Scaffolding (Sumber : dokumen penulis,2018)

Untuk mengubah rumah scaffolding sederhana menjadi menjadi lebih besar yaitu dengan menambahkan jumlah material scaffolding sebagai pondasi utama, semakin banyak scaffolding yang disusun maka semakin luas lahan yang digunakan. Kemudian untuk menarik minat calon penghuni, rumah scaffolding didesain semenarik mungkin. Memberikan aksen hunian minimalis dan tropis. Berada di daerah beriklim tropis, hunian ini dirancang agar mampu beradaptasi dengan lingkungan, serta penghuni mampu mendapatkan kenyamanan secara maksimal. Mulai dari penataan denah rumah, program ruang, sirkulasi udara dan pencahayaan mempertimbangkan kesesuaian dengan iklim dan cuaca yang ada.

\section{Kualitas Material}

Scaffolding sebagai bahan utama perancangan rumah scaffolding sekaligus sebagai struktur bangunan yang berfungsi melindungi suatu ruangan terhadap iklim,bahaya yang ditimbulkan alam dan untuk menyalurkan beban ke dalam tanah, harus memiliki spesifikasi sebagai jaminan daya tahan. Scaffolding merupakan sejenis besi sehingga harus diberi cat (anti karat) agar dapat bertahan selama bertahun-tahun.

\section{Estimasi Biaya Rumah Scaffolding}

Tabel 1. Perkiraan Harga Material untuk Rumah Scaffolding Tipe 36

\begin{tabular}{|r|l|l|l|}
\hline & & \multicolumn{2}{|c|}{ Rumah scaffolding } \\
\hline No & Pekerjaan & \multicolumn{1}{|c|}{ Material } & $\begin{array}{c}\text { Perkiraan } \\
\text { harga }\end{array}$ \\
\hline 1 & PONDASI & Semen & Rp 600.000 \\
\hline & & Pasir & Rp 300.000 \\
\hline
\end{tabular}




\begin{tabular}{|c|c|c|c|}
\hline & & \multicolumn{2}{|c|}{ Rumah scaffolding } \\
\hline \multirow[t]{3}{*}{ No } & Pekerjaan & Material & $\begin{array}{c}\text { Perkiraan } \\
\text { harga }\end{array}$ \\
\hline & & Kerikil & $\mathrm{Rp} \quad 300.000$ \\
\hline & & Besi Beton & $\operatorname{Rp} 2.000 .000$ \\
\hline \multirow[t]{5}{*}{2} & DINDING & Scaffolding & Rp 2.000.000 \\
\hline & & Wiremesh & $\mathrm{Rp} 1.260 .000$ \\
\hline & & Zincalum & Rp 1.800 .000 \\
\hline & & Papan Kayu & $\mathrm{Rp} \quad 400.000$ \\
\hline & & $\begin{array}{l}\text { Anyaman } \\
\text { Bambu }\end{array}$ & $\mathrm{Rp} \quad 300.000$ \\
\hline \multirow[t]{2}{*}{3} & LANTAI & $\begin{array}{l}\text { Rangka Baja } \\
\text { Kanal }\end{array}$ & $\mathrm{Rp} \quad 185.000$ \\
\hline & & Rangka Kayu & Rp $\quad 200.000$ \\
\hline \multirow[t]{3}{*}{4} & ATAP & $\begin{array}{l}\text { Kuda-kuda } \\
\text { hollow }\end{array}$ & $\mathrm{Rp} \quad 142.800$ \\
\hline & & Penutup Atap & $\mathrm{Rp} \quad 540.000$ \\
\hline & & Paku & $\mathrm{Rp} \quad 400.000$ \\
\hline \multirow[t]{6}{*}{5} & FINISHING & Kusen Pintu & Rp 1.800 .000 \\
\hline & & $\begin{array}{l}\text { Kusen } \\
\text { Jendela } \\
\end{array}$ & Rp $\quad 800.000$ \\
\hline & & Kunci Engsel & Rp $\quad 500.000$ \\
\hline & & $\begin{array}{l}\text { Pintu Kamar } \\
\text { Mandi }\end{array}$ & $\mathrm{Rp} \quad 150.000$ \\
\hline & & Closet & $\mathrm{Rp} \quad 100.000$ \\
\hline & & Cat Minyak & Rp $\quad 250.000$ \\
\hline \multirow[t]{2}{*}{6} & UTILITAS & Instalasi Pipa & Rp $\quad 500.000$ \\
\hline & & $\begin{array}{l}\text { Instalasi } \\
\text { Listrik }\end{array}$ & $\mathrm{Rp} \quad 500.000$ \\
\hline & TOT & & Rp15.027.800 \\
\hline
\end{tabular}

(Sumber : akanoma studio,2018)

Berikut adalah tabel estimasi perkiraan sementara untuk rumah scaffolding ukuran $6 \times 6$ meter. Tabel hanya menunjukkan harga material saja tanpa perhitungan harga tanah, upah pekerja dan pekerjaan lainnya. Dari data tersebut dapat dibandingkan harga rumah biasa dengan estimasi biaya sekitar 40 juta sampai 50 juta dengan rumah scaffolding estimasi biaya kurang lebih 15 juta (menurut tabel di atas), dengan ukuran yang sama (tipe 36). Kemudian dapat diambil kesimpulan bahwa rumah scaffolding lebih ekonomis dari segi biaya. Hal ini juga menjadi point utama dipilihnya rumah scaffolding untuk masyarakat berpenghasilan rendah (MBR) agar terhindar dari riba (bunga) karena cicilan rumah pada umumnya yang mahal.

\section{Lingkup dan Sasaran}

Lingkup dan sasaran rumah scaffolding adalah semua kalangan masyarakat ekonomi rendah di daerah perkotaan. Khusunya masyarakat yang tinggal di permukiman kumuh dan masyarakat yang menempati wilayah ilegal. Mulai dari kalangan yang tinggal di daerah bantaran sungai, pinggir rel kereta api, bawah kolong jembatan dan pasangan suami istri muda yang baru menikah namun belum mampu untuk membangun rumah sendiri. Dengan adanya rumah scaffolding diharapkan dapat membantu menyediakan fasilitas tempat tinggal yang efektif dan hemat biaya.

\section{KESIMPULAN}

Penelitian yang dilakukan memperoleh hasil bahwa rumah scaffolding memiliki karakteristik mudah untuk dirakit, dibongkar, dimodifikasi dan menciptakan desain eksplorasi yang tidak terbatas. Penampilan dari fasad mengambil sebagian besar varietas dari bahan alam lokal. Berbagai jenis material bangunan, scaffolding memiliki berbagai keunggulan. Diantaranya adalah yang disebutkan di atas, yaitu dapat dirakit dengan cepat dan mudah, tersedia dibanyak kota besar, ukuran modulnya cukup nyaman untuk ruang gerak, dapat berfungsi sebagai struktur rumah dengan konstruksi berbeban ringan, dapat dibongkar pasang, dan dapat bertumbuh atau dikembangkan.

Perencanaan rumah scaffolding ini dirancang untuk membantu kalangan masyarakat masyarakat ekonomi rendah sebagai rekomendasi perancangan alternatif hunian hemat biaya dan anti riba. Namun dalam penelitian ini terdapat kelemahan yaitu, kekuatan yang dimiliki rumah scaffolding belum diketahui, karena belum dilakukan pengujian secara teknis sehingga rumah ini hanya dapat direkomendasikan untuk rumah sementara yang bertahan beberapa tahun saja, untuk membantu masyarakat kurang mampu mendapatkan hunian sebelum memiliki biaya yang cukup untuk membangun rumah yang lebih baik.

\section{DAFTAR PUSTAKA}

Fatwa DSN-MUI no.1 tahun 2004.

Frick, H. (2006). Pola Struktur dan Teknik Bangunan di Indonesia. University Press Yogyakarta.

Frick, H., FX, \& Suskivatno, B. (1998). Dasar-Dasar Eko-Arsitektur, Konsep Arsitektur Berwawasan Lingkungan Serta Kualitas Konstruksi dan Bahan Bangunan Untuk Rumah Sehat. Semarang: Soegijapranata University Press.

Ikhsanudin, K. (2017). Dasar Program Perencanaan dan Perancangan Arsitektur (DP3A). Tanjung Emas Container Apartement, 8-13.

Kementrian Agama RI. 2014. Al-Quran Terjemah. Bandung: Sygma Creative Media Corp. 
KEMENKES RI. 2007 . Syarat Rumah Sehat. Jakarta : Direktorat Jendral Pengendalian Penyakit dan Penyehatan Lingkungan (Ditjen PPPL).

Neufert, E. (2002). Data Arsitek Terjemah oleh Tjahjadi, Sunarto, Chaidir, Ferryanto. Jakarta: Erlangga.

Rataru, R. (1996). Handbook of Temporary Structures in Conctruction. United Stated: The McGraw-Hill.

Richard Untermann dan Robert Small. (1986). Perencanaan Tapak untuk Perumahan. Malang: Intermata.

Rully. (2014). Merencanakan dan Merancang Rumah Tinggal yang Optimal, 13.

Soemardi, R. (1992). Manajemen Proyek Pembangunan, Konsep dan Beberapa Studi Kasus di Indonesia. Jakarta: Fakultas Ekonomi Universitas Indonesia. 